\title{
Seasonal and Temporal Variations in the Population and Biting Habit of Mosquitoes on the Atlantic Coast of Lagos, Nigeria
}

\author{
B.M. Afolabi ${ }^{a, c}$ C.N. Amajoh ${ }^{d}$ T.A. Adewole ${ }^{a}$ L.A. Salako ${ }^{b}$ \\ ${ }^{a}$ Nigerian Institute of Medical Research, Yaba, ${ }^{b}$ Federal Vaccine Production Laboratory, Yaba, \\ ${ }^{c}$ World Health Organization, Yaba, Lagos, and ${ }^{\mathrm{d}}$ Malaria and Vector Control Unit, Federal Ministry of Health, \\ Abuja, Nigeria
}

\section{Key Words}

Entomological inoculation rate $\cdot$ Anopheles gambiae complex $\cdot$ Malaria $\cdot$ Human-biting rate $\cdot$ Mosquito density $\cdot$ Nigeria, coast of

\begin{abstract}
Objectives: To determine the hourly density of vector mosquitoes in coastal Nigeria, compare seasonal human-biting and sporozoite rates in the vector density, locate breeding sites of mosquitoes, and determine larval population at breeding sites. Materials and Methods: Indoor and outdoor mosquitoes of a coastal Nigerian community were caught during early and late wet seasons and in the harmattan period, a time of dusty wind from the Sahara on the western coast of Africa. Larvae were collected from various locations during the study period. The mosquitoes were physically characterized and their salivary glands dissected for sporozoite rate. Larvae density was calculated. Human-biting rate was calculated for Anopheles gambiae complex. Results: Of the 4,317 female $A$. gambiae complex collected during the night bait catches, 3,543 (82.1\%) were from outdoors and $774(17.9 \%)$ from indoors during the three seasons. The maximum human-biting rate approached $25 / \mathrm{h}$ and the sporozoite rate was almost $3.0 \%$. These vector mosquitoes were mainly outdoor biting and midnight feed-
\end{abstract}

ing. Of the 1,269 Anopheles mosquitoes collected with pyrethrum spray catches, 1,245 (98.1\%) were A. gambiae complex. There was no significant difference in the entomological inoculation or sporozoite rates during the three seasons of study. There was a preponderance of A. gambiae complex larvae from larval collection. Conclusion: Findings from this study should be useful in the implementation of Integrated Vector Management for the control of malaria in coastal and noncoastal areas of Nigeria.

Copyright $\odot 2006$ S. Karger AG, Basel

\section{Introduction}

Since the beginning of the 20th century, a great deal of attention has been paid globally to the control of malaria vectors. The Lagos Mosquito Control Scheme of swamp drainage began in 1942 as a limited project and was eventually completed by the end of 1947 . This scheme, which extended over an area of nearly 4,200 acres of coastal swamps, was executed with a view to controlling the breeding activity of mosquitoes, at first near the Royal Air Force Airport at Apapa (Lagos) and later in the urban area proper. The drainage scheme, designed and executed by Gilroy, consisted of (a) a sea-wall or bund that enclosed the low-lying swamp and prevented the tidal waters from

\section{KARGER}

Fax +4161306 1234 E-Mail karger@karger.ch www.karger.com 
flooding it, (b) a system of channels and contour drains that led the impounded water to (c) a controlled outlet in the form of hand-operated sluice-gates [1]. The success of this scheme was striking with regard to the control of various vector mosquitoes of human malaria in its main breeding areas. As data have been accumulating on the biology and behavior of these vectors mosquitoes in all phases of their development, it has become easier to plan vector control measures as efficiently as possible, to establish their proper timing and to develop better methods of entomological evaluation of the effectiveness of applied methods [2]. The better the knowledge of transmission dynamics, the more appropriate the choice of control measures and the more successful the outcome [3]. Ideally, Integrated Vector Management is advocated.

In recent years, very few studies have been carried out in Nigeria to address the behavior of vectors of human malaria in the light of malaria control actions presently ongoing in the country. Large field studies on the transmission of malaria in different geographical zones of Nigeria had earlier been carried out [4], which showed that both Anopheles gambiae s.s. and Anopheles arabiensis were present in the Sudan Savannah ecological zone of Nigeria, with $A$. arabiensis being the dominant species [5]. In Southeast Nigeria, another study described the prevalence of female Anopheles mosquito infection with human Plasmodium parasites [6].

Since the 1980s, there have been few studies on the distribution of mosquito vectors in the different ecological zones of the country. Understanding the spatiotemporal distribution of risk of mosquito-borne infection is an important step in planning and implementing effective infection control. The objectives of the present study were to determine the predominant mosquito species on the coastal ecosystem, verify through night bait catches hourly mosquito density on the Atlantic coast of Nigeria in different seasons - early wet season (EWS), dry harmattan season (DHS) and late wet season (LWS), compare seasonal human-biting rate, the proportion of infectious mosquitoes (sporozoite rate) and entomological inoculation rate (EIR) of important vector mosquitoes of human malaria and locate the breeding sites of and identify the larvae of these vectors of human malaria.

\section{Materials and Methods}

Study Area

The study was carried out at Ibeshe Island on the Atlantic coast of Nigeria in the extreme southwestern corner of Nigeria. The Lagos lagoon surrounding this island is frequently admixed with the salty ocean water, raising the possibility of the domination of the saltwater breeding species: A. gambiae var. melas over other vectors of malaria parasites there. Most of the houses at the study site were built with bricks and roofed with corrugated iron sheets. The average size of a room was about $4 \times 3 \mathrm{~m}$. Most of the walls were cement-plastered with at least two windows and a door per room. Very few rooms had intact window or door netting materials. Some houses had thatched roofing.

\section{Study Population}

This community, described in an earlier study [7], is a fishing population made up mostly of the Aworis, an ethnic subgroup of the Yoruba, the major ethnic group in southwest Nigeria. Literacy rate of women $(45 \%)$ was lower than that of men $(52 \%)$ [8]. The population of the Ibeshe community, consisting mostly of fishermen and boat builders, was about 5,000 (1993 National Population Census). The commonest health complaints brought to the single health center in this community were fever, malaria, diarrhea, jaundice, cough and measles.

\section{Sampling Methodology}

A list of all the houses in the community, as compiled by the National Primary Health Care Development Agency, was obtained, from which our sample size of 50 houses for night bait catches (NBC) was drawn by simple random sampling. All selected households voluntarily agreed to participate in the survey. The study area was thereafter randomly divided into three parts: nearest to the Atlantic ocean (south), farthest from the ocean (north), and the central area, which included the community leader's residence.

\section{Selection of Field Workers}

Three field workers for the survey were carefully selected from the entomology unit of the Malaria and Vector Control Division of the Federal Ministry of Health. They had been conducting entomological surveys for over a decade under close supervision of top malariologists in Nigeria. Because the survey required that they stay outdoors during NBC, each one of them was skilled in dissecting the salivary gland and the mid-gut of the mosquito for microscopic identification of the mosquito stages of the parasites. In addition, they were all competent with the use of the ladle in the survey of mosquito larvae. Nevertheless, they undertook, under supervision, one NBC and one pyrethrum spray catch (PSC) followed by visual and laboratory microscopic examination of the captured mosquitoes and correct reporting of their findings, at the Nigerian Institute of Medical Research before they were deployed to the field.

\section{Entomological Survey}

Equipment used for the NBC consisted of a long flexible rubber tube to which a hollow glass rod was attached at one end and a mouthpiece at the other. The glass rod contained a bulb in its middle section packed with cotton wool such that mosquitoes sucked into the rod were trapped in the bulb. For the PSC, floors of selected rooms were covered with clean white sheets sprayed with pyrethrum. After about $15 \mathrm{~min}$, the sheets were carefully removed outdoors and inspected to collect all mosquitoes that had been knocked down on them. Female mosquitoes were morphologically identified microscopically [9]. These entomological examinations were made under the following conditions as reported in the Garki Project [5]: (a) The houses used for NBC and PSC were regularly 
inhabited. On the night of the NBC they were vacated by their normal inhabitants and occupied by the bait collectors and (b) no home was used for more than one type of study (NBC or PSC).

\section{Entry into the Community}

One researcher (B.M.A.) had been working in this community for 4 years thus facilitating smooth entry into the community. The traditional ruler and his council were first informed of the exercise, which they approved. The traditional ruler also volunteered to have his house included among the study houses. The heads of houses that were randomly selected for the survey were notified and most agreed. The few that refused gave various reasons ranging from fear of the effect of the insecticide to absence of decision-maker in the house. The nearest house to these was then chosen to replace the refusals.

\section{Ethical Issues: Community and Household Consent}

The community head was first approached and informed about the project, to which he consented. Heads of households of selected houses were informed of the project first by the community head and thereafter by the principal investigator of the project. Verbal consent was given by heads of the selected households for their houses to be used for the study.

PSC: Spraying with Insecticides and Collection of Mosquitoes

The methods used were as described in the Manual on Practical Entomology in Malaria [10]. For PSC, clean white sheets were spread on the floor of each room in the selected houses before spray so as to easily see and collect mosquitoes after spraying the rooms with insecticides. Mosquitoes collected were identified and counted; females were classified by stages of abdominal appearance and when feasible dissected for sporozoite examination. Very infrequently, one house had to be replaced by another resembling it as closely as possible. PSCs were conducted after people had slept in the room the previous night.

\section{Night Bait Catches}

These were carried out in the same locality where the PSC were done. The first NBC was carried out for 2 consecutive nights, spending $9 \mathrm{~h}$ each night ( 7.00 p.m. to 4.00 a.m.). One of the field workers was selected for indoor catches, while the other 2 were for outdoor catches. The weather was favorable for the survey. Each catcher sat quietly in the test area scantily clothed to expose the limbs. Mosquitoes that bit or landed to bite were collected (using the collection tube), counted, stored in a refrigerated paper box and later identified. Indicated on the paper boxes specially made to collect the mosquitoes were date, time and place of collection. Number of mosquitoes landing within the period of time was recorded in a notebook supplied to each catcher.

In each study period, the salivary glands of identified female mosquitoes from outdoor collections [204 (53.3\%) in the late wet season in September, $105(8.3 \%)$ in the dry and dusty harmattan season in January, and $240(12.7 \%)$ in the early wet season in May] and indoor collections [151 (83.0\%), $45(14.1 \%)$ and $100(36.6 \%)]$ as well as those from PSC [300 (59.1\%), $295(67.7 \%)$ and 280 (75.1\%)]) were dissected using disposable $25 \mathrm{G}$ syringe needles. These were examined for sporozoites only. Overall, the salivary glands of $845(19.6 \%)$ of mosquitoes caught during the NBC and $875(70.3 \%)$ of those caught during the PSC were dissected and examined for sporozoites.

\section{Larval Survey}

The first larval collections were carried out in January 1998 and the second in May of the same year in the same area and within $1 \mathrm{~km}$ radius of the center of the community where there were pockets of stagnant water, e.g. in serviceable and unserviceable wooden canoes on the lagoon shore, broken pots, pools and trenches. Larval collections were carried out between the hours of 11.00 a.m. and 5.00 p.m. At each collection, the ladle was dipped a total of 40 times into each location of stagnant water. A hand lens was used in the field to identify and characterize the collected larvae.

\section{Data Analysis}

The total number of mosquitoes collected was recorded on a spreadsheet and divided into their respective species. Density of the PSC in the rooms sprayed was calculated by a hand-held calculator and expressed as mosquitoes per day per room. Human-biting rate of mosquitoes caught during the NBC was calculated and expressed as mosquitoes per man per hour. EIR was expressed as human-biting rate multiplied by sporozoite rate.

\section{Definitions}

A gravid female mosquito is taken to be one with a milky abdomen. A gravid female mosquito can be either fully gravid, whereby the abdomen is completely milky and bulging, or half gravid where the abdomen is partly milky and partly reddish. A blood-fed female mosquito has a fully reddish bulging abdomen, whereas an unfed mosquito has a flat and dark reddish abdomen.

\section{Results}

Each of the 3 human baits spent $132 \mathrm{~h}$ collecting the mosquitoes during NBC. Table 1 shows the profiles of both outdoor and indoor mosquitoes collected during NBC throughout the study period at the study site. A. gambiae complex was the dominant species throughout the three study seasons, accounting for 94.2 and $90.4 \%$ of all outdoor and indoor NBC, respectively. The population density of outdoor and indoor $(1,335 ; 343)$ NBC during DHS was significantly higher $\left(\chi^{2}=31.6 ; \mathrm{p}<\right.$ $0.001)$ than that during LWS $(400 ; 187)$, but significantly lower $\left(\chi^{2}=30.6 ; p<0.001\right)$ than that in the EWS $(2025$; $326)$. There was no significant difference in outdoor or indoor human-biting rates in any of the different seasons, though these were more pronounced during the DHS (24.7 mosquitoes/man/h) than in the EWS or in the LWS. Sporozoite rates of indoor NBC were generally higher than those of outdoor NBC except during the LWS. EIR values of outdoor NBC were significantly higher than those from indoor catches. The nocturnal exophilic and endophagic behavioral patterns of the mosquitoes collected were mostly pronounced during the DHS and during the EWS. 
Table 1. Profiles of outdoor and indoor mosquitoes collected during NBC on the Atlantic coast of Lagos, Nigeria, during the study period

\begin{tabular}{|c|c|c|c|c|c|c|}
\hline & \multicolumn{6}{|c|}{ Total mosquitoes collected } \\
\hline & \multicolumn{2}{|c|}{ LWS (September) } & \multicolumn{2}{|c|}{ DHS (January) } & \multicolumn{2}{|c|}{ EWS (May) } \\
\hline & outdoor & indoor & outdoor & indoor & outdoor & indoor \\
\hline Total mosquitoes collected & 400 & 187 & 1,335 & 343 & 2,025 & 326 \\
\hline Total hours used for collection & 18 & 18 & 18 & 18 & 30 & 30 \\
\hline Collectors & 3 & 3 & 3 & 3 & 3 & 3 \\
\hline Total female $A$. gambiae complex collected & 383 & 82 & 1,266 & 319 & 1,894 & 273 \\
\hline Percent $A$. gambiae complex collected & 94.1 & 96 & 94.8 & 93.3 & 93.5 & 83.7 \\
\hline Human-biting rate, mosquito/man/h & 7.4 & 3.5 & 24.7 & 5.9 & 22.5 & 3.6 \\
\hline Total $A$. gambiae complex dissected & 204 & 151 & 105 & 45 & 240 & 100 \\
\hline Total positive of sporozoites & 6 & 2 & 2 & 1 & 6 & 3 \\
\hline Sporozoite rate, $\%$ & 2.9 & 1.3 & 1.9 & 2.2 & 2.5 & 3 \\
\hline Entomological inoculation rate & 21.5 & 4.64 & 6.9 & 13 & 56.3 & 10.8 \\
\hline
\end{tabular}

Table 2. Characteristics of mosquitoes collected at a 3-day daytime PSC during the survey period

\begin{tabular}{|c|c|c|c|c|c|c|c|c|c|c|c|c|}
\hline & total & blood-fed & empty & gravid & total & blood-fed & empty & gravid & total & blood-fed & empty & gravid \\
\hline A. funestus ${ }^{1}$ & 2 & 1 & 1 & - & 3 & 1 & - & 2 & 7 & 2 & 2 & 3 \\
\hline A. nili ${ }^{1}$ & - & - & - & - & 5 & 4 & 1 & - & - & - & - & - \\
\hline A. moucheti ${ }^{1}$ & 1 & - & 1 & - & 3 & 2 & 1 & - & 3 & 2 & 1 & - \\
\hline \multicolumn{13}{|l|}{ Aedes aegypti } \\
\hline Female & 6 & - & 6 & - & 7 & - & 7 & - & 41 & - & 41 & - \\
\hline Male & 2 & - & 2 & - & 8 & - & 8 & - & 14 & - & 14 & - \\
\hline \multicolumn{13}{|l|}{ Culex pipiens quinquefasciatus } \\
\hline Female & 1 & - & 1 & - & 22 & - & 22 & - & 1 & - & 1 & - \\
\hline Male & 2 & - & 2 & - & 13 & - & 13 & - & 11 & - & 11 & - \\
\hline Total & 522 & 448 & 21 & 53 & 438 & 263 & 82 & 93 & 437 & 275 & 115 & 46 \\
\hline \multicolumn{13}{|l|}{ A. gambiae complex, $\%$} \\
\hline Positive sporozoites, $\mathrm{n}$ & \multicolumn{4}{|c|}{7} & \multirow{2}{*}{\multicolumn{4}{|c|}{6}} & \multicolumn{4}{|c|}{7} \\
\hline Sporozoite rate, $\%$ & \multicolumn{4}{|c|}{2.3} & \multicolumn{3}{|c|}{2.0} & & \multicolumn{4}{|c|}{2.5} \\
\hline
\end{tabular}

${ }^{1}$ Female (male $A$. gambiae, $A$. funestus, $A$. nili and $A$. moucheti collected were few and thus disregarded in this analysis).

The characteristics of mosquitoes collected at a 3-day PSC in each of the three study periods are illustrated in table 2 . A vast majority of the mosquitoes collected during the PSC were A. gambiae complex of which $97.3 \%$ were collected in the LWS, $86.1 \%$ in the DHS and $82.3 \%$ in the EWS. Almost all were blood-fed as well as gravid. The largest number of Anopheles funestus was collected during the EWS, while Anopheles nili was present only during the DHS. Sporozoite rate was highest $(2.5 \%)$ in the EWS. Larvae of $A$. gambiae complex were collected during the EWS but not during the DHS. The cumulative hourly mosquito density (\%) during outdoor and indoor $\mathrm{NBC}$ in the study period is shown in table 3. In general, while outdoor hourly mosquito density was higher than 
Fig. 1. Percent distribution of outdoor and indoor hourly biting cycles of mosquitoes from NBC on the Atlantic coast of Nigeria during LWS (1998). $\boldsymbol{\square}=$ Outdoor NBC; $\boldsymbol{\Delta}=$ indoor NBC.

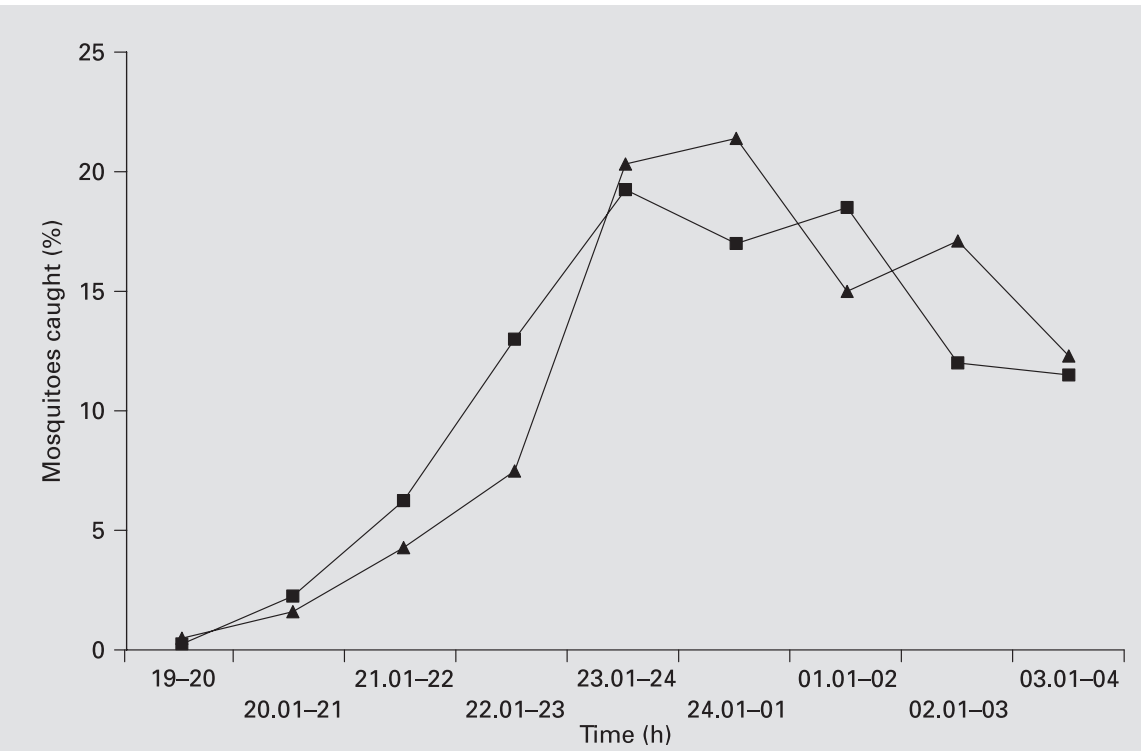

Table 3. Cumulative hourly mosquito density (\%) in outdoor and indoor NBCs in LWS, DHS and EWS on the Atlantic coast of Nigeria

\begin{tabular}{|c|c|c|c|c|c|c|c|c|c|c|c|c|c|c|c|}
\hline \multirow[t]{2}{*}{ Hour of NBC } & \multicolumn{5}{|c|}{$\begin{array}{l}\text { LWS (September) } \\
\text { mosquito density, \% }\end{array}$} & \multicolumn{5}{|c|}{$\begin{array}{l}\text { DHS (January) } \\
\text { mosquito density, \% }\end{array}$} & \multicolumn{5}{|c|}{$\begin{array}{l}\text { EWS (May) } \\
\text { mosquito density, } \%\end{array}$} \\
\hline & OD & ID & $\chi^{2}$ & $\mathrm{p}$ & OR & OD & ID & $\chi^{2}$ & $\mathrm{p}$ & OR & OD & ID & $\chi^{2}$ & $\mathrm{p}$ & OR \\
\hline $19.00-20.00 \mathrm{~h}$ & 0.3 & 0.5 & 0.3 & 0.6 & 0.5 & 0.8 & 1.6 & 1.2 & 0.3 & 0.6 & 1.7 & 4.3 & 9.9 & 0.002 & 0.37 \\
\hline $20.01-21.00 \mathrm{~h}$ & 2.3 & 1.6 & 0.1 & 0.8 & 1.2 & 6.7 & 2.0 & 7.1 & 0.008 & 2.3 & 5.8 & 6.1 & 3.5 & 0.06 & 0.69 \\
\hline $21.00-22.00 \mathrm{~h}$ & 6.3 & 4.3 & 0.9 & 0.3 & 1.4 & 7.2 & 3.5 & 14.4 & 0.0001 & 2.3 & 8.8 & 9.2 & 2.3 & 0.13 & 0.79 \\
\hline $22.01-23.00 \mathrm{~h}$ & 13.0 & 7.5 & 5.1 & 0.02 & 1.7 & 10.4 & 8.8 & 14.4 & 0.001 & 2.3 & 9.5 & 11.0 & 3.5 & 0.06 & 0.78 \\
\hline $23.01-24.00 \mathrm{~h}$ & 19.3 & 20.3 & 2.5 & 0.1 & 1.3 & 15.7 & 9.9 & 13.5 & 0.002 & 1.8 & 14.2 & 10.4 & 0.2 & 0.63 & 0.94 \\
\hline $24.01-01.00 \mathrm{~h}$ & 17.0 & 21.4 & 0.3 & 0.6 & 1.1 & 20.9 & 24.2 & 26.6 & 0.000 & 2.0 & 16.9 & 13.2 & 0.7 & 0.39 & 1.11 \\
\hline $01.01-02.00 \mathrm{~h}$ & 18.5 & 15.0 & 2.4 & 0.1 & 1.4 & 17.2 & 26.2 & 16.0 & 0.000 & 1.6 & 16.9 & 6.4 & 23.6 & 0.000 & 1.81 \\
\hline $02.01-03.00 \mathrm{~h}$ & 12.0 & 17.1 & 0.8 & 0.8 & 1.8 & 12.2 & 13.7 & 1.3 & 0.3 & 1.2 & 9.6 & 13.8 & 15.0 & 0.0001 & 1.71 \\
\hline $03.01-04.00 \mathrm{~h}$ & 11.5 & 12.3 & 0.8 & 0.8 & 0.9 & 8.8 & 10.2 & 0.7 & 0.4 & 1.2 & 8.9 & 12.3 & 10.6 & 0.001 & 1.80 \\
\hline
\end{tabular}

$\mathrm{OD}=$ Outdoor; ID = indoor; OR = odds ratio.

indoor mosquito density in early evenings (between 20.01 and $24.00 \mathrm{~h}$ ), indoor mosquito density was higher than outdoor mosquito density especially during the early hours of the day (between $24.00 \mathrm{~h}$ and $04.00 \mathrm{~h}$ ). During the LWS, especially before midnight, mosquitoes were about twice as likely to be found in significant numbers indoors than outdoors. In general, during the DHS, mosquitoes were twice as likely to be found indoors than outdoors between 20.01 and $02.00 \mathrm{~h}$ and between 01.01 and $04.00 \mathrm{~h}$. During LWS, peak outdoor and indoor biting time was between 23.00 and $24.00 \mathrm{~h}$, as shown in figure 1 .
Indoor mosquito density was less than that of outdoor between 19.00 and $23.01 \mathrm{~h}$. There was, thereafter, a transient increase in the percent of mosquitoes caught indoors compared to those caught outdoors. Initially, there was no significant difference in hourly outdoor and indoor mosquito population until $23.00 \mathrm{~h}\left(\chi^{2}=5.05 ; \mathrm{p}=0.03\right)$ and $01.00 \mathrm{~h}\left(\chi^{2}=3.69 ; \mathrm{p}=0.05\right)$, when this became obvious. A step-ladder decrease in both outdoor and indoor mosquito density was observed between 24.00 and $03.00 \mathrm{~h}$, indicating the possibility of an exchange of feeding pattern between mosquitoes indoors and those out- 
Fig. 2. Percent distribution of indoor and outdoor hourly biting cycles of mosquitoes from NBC on the Atlantic coast of Nigeria during DHS (1998). $\boldsymbol{\square}=$ Outdoor NBC; $\boldsymbol{\Delta}=$ indoor NBC.

Fig. 3. Percent distribution of outdoor and indoor hourly biting cycles of mosquitoes from NBC on the Atlantic coast of Nigeria during EWS (April-June). $\boldsymbol{\square}=$ Outdoor $\mathrm{NBC} ; \boldsymbol{\Delta}=$ indoor NBC.


doors. The percent distribution of outdoor and indoor hourly biting cycles of mosquitoes from NBC during the DHS is shown in figure 2. By $21.00 \mathrm{~h}$ there was already a noteworthy disparity $\left(\chi^{2}=7.10 ; p=0.008\right)$ between the outdoor $(101 / 1,341)$ and indoor $(12 / 343)$ mosquito den- sity. This trend continued, hourly, until $01.00 \mathrm{~h}$ at which time the indoor mosquito population surpassed outdoor mosquito population. The indoor mosquito biting cycle peaked between 01.01 and $02.00 \mathrm{~h}$, while the outdoor mosquito biting cycle peaked an hour earlier. Between the 
hours of 01.01 and 04.00 , there was a parallel decline in both outdoor and indoor mosquito density. In EWS there was an initial disparity $\left(\chi^{2}=9.94 ; p=0.002\right)$ between the outdoor and indoor mosquito density in early evening (19.00-20.00 h), but this was not maintained until between 01.01 and $02.00 \mathrm{~h}$ when this disparity was evident $\left(\chi^{2}=23.56 ; \mathrm{p}<0.0001\right)$ till $05.00 \mathrm{~h}\left(\chi^{2}=10.56 ; \mathrm{p}=0.001\right)$ (fig. 3).

\section{Larval Survey}

The total number of larvae collected during the DHS was 50, none of which belonged to the Anopheles species but to that of Aedes aegypti. These same sites were revisited during the EWS for daytime (11.30 a.m. and 5.00 p.m.) collection where, from 120 dips, 288 larvae were collected out of which 284 or $98.6 \%$ (2.4 per dip) were those of A. gambiae complex.

\section{Discussion}

To be vectors of human malaria, mosquitoes of Anopheles complex species are expected to bite humans not sporadically, i.e. they have to be characterized by intrinsic behavioral patterns determining their association with both the human and the human host. Although easier to be bitten because of their almost hairless skin, humans actually constitute a rather difficult target for blood-feeding arthropods, mainly because of cultural adaptations enhancing various host defense mechanisms. For example, to reach humans when they sleep indoors requires the development of the capacity to penetrate inside a room and bite humans there, i.e. endophagy, a specific behavioral trait never evolved in some hematophagous Diptera such as Tabanidae, Glossinidae and Simuliidae [11], though typically these are present in many endemic malaria areas.

The epidemiological effectiveness of a mosquito vector depends on many factors. Among the more important are the total number of mosquitoes, the degree of their contact with man, their life span and their susceptibility to infection with plasmodia [2]. The mosquito vectors which are largely responsible for transmission of malaria in Nigeria - A. gambiae s.l., and A. funestus - breed in fairly clean, sunlit, small collections of standing water [10]. A. gambiae s.l. is a complex of at least 6 sibling species [12]. Mosquitoes of this species are widespread throughout tropical Africa except in the Sahel [10]. A. gambiae complex includes 2 species that breed in salt water: Anopheles melas in West Africa and A. merus in
East Africa [13]. The high percentage of A. gambiae complex collected in this study is normal for the coastal ecotype, similar to a report from Senegal [http://www.netmarkafrica.org/countries/senegal/briefbook/senegal_ english_briefing_book.doc]. Sporozoite rates in the present study were higher than in the Garki Project in Northern Nigeria [5]. One of the major observations elaborated in our study is outdoor biting and midnight feeding habits of mosquitoes in the coastal community. The biting times of the African malaria vectors and other 'pest' mosquitoes are well documented. The results of our study were considered to be useful in planning the control of malaria in coastal and other ecological zones of Nigeria and implementing these plans within the context of the Roll Back Malaria Initiative using the Integrated Vector Management approach.

The risk of a mosquito-borne infection is estimated by the EIR: the number of bites by infectious mosquitoes per person per day [14]. EIR is the product of the human-biting rate - the number of bites by vector mosquitoes per person per day - and the proportion of mosquitoes that are infectious (e.g., for malaria transmission, the sporozoite rate) [15]. Outdoor EIR in our study was most pronounced in the EWS and in the DHS. Morbidity is expected to be high at this time. EIR is generally considered to be the best estimate of the risk of mosquito-borne infections, but EIR varies over space and time. EIR varies spatially because larval habitat and blood-meal hosts are heterogeneously distributed across a landscape. Temporal variability is generally driven by weather, especially rainfall, temperature, and humidity [16]. To compound the problem, heterogeneity in human feeding over short distances can be caused by vector preferences for individual humans based on odor or other cues $[17,18]$. Heterogeneous biting has important implications for the dynamics and control of mosquito-borne infections [1921].

It is interesting to note that, in each of the seasons, especially between 19.00 and $20.00 \mathrm{~h}$, indoor mosquito density was greater than that outdoor, though the difference was insignificant. Could these be sentinel or advance-party mosquitoes surveying for available human blood meals and reporting back? There is need for more study on this aspect of seemingly irrelevant mosquito bionomics. However, it has been argued that generally the first host cues to reach a mosquito are volatile chemicals emanating from the skin, breath and waste products of a potential host [22] carried by air currents. The probability that the mosquito responds to these cues and the intensity of its response depend on the strength of host-de- 
rived stimuli, of the competing external stimuli (e.g. odors from other sources, prohibitive wind speeds, etc.), its internal state (e.g. circadian phase, gonotrophic and nutritional status, etc.), and its genotype (i.e. the genetic component of the responsiveness to given stimuli) [11].

The study of the feeding habits of the main Afro-tropical malaria vectors throughout their distribution has been traditionally based on the identification of blood meal origin of field-collected mosquitoes. The main shortcoming of this study was that polymerase chain reaction was not used to identify various species of Anopheles vectors at the coastal area and to certify whether their blood meal is from human or animal origin, though animals such as cattle, donkeys and goats are rare in the study site but pigs and dogs are more common. A. gambiae var. melas is, however, suspected to be the dominant species in this ecosystem since it breeds in salt water.

Aedes aegypti is historically the primary vector for the viruses that cause human dengue and yellow fever. It is a medium-sized blackish mosquito easily recognized by a silvery-white 'lyre-shaped' pattern of scales on its scutum. It thrives in intimate association with humans and is the vector of the virus of urban yellow fever, a vaccine-preventable disease [15] that occurs in epidemics in Nigeria. In general this is a species that creates a great level of nuisance and has great capacity for energetic migration. It can cover distances of more than $20 \mathrm{~km}$. Mosquitoes that belong to this genus lay their eggs on periodically flooded ground. Flooding brings about massive simultaneous hatches while eggs can remain lethargic for several years until they meet the appropriate conditions for hatching. Apart from the high level of nuisance, they can be hosts for arboviruses as well as filariasis. Aedes aegypti is considered the main host of dengue and yellow fever, which should alert us to the potential for yellow fever epidemics in the country.

Culex pipiens, found on the field in our study, is the most widely distributed mosquito in the world. It is found on every continent except Antarctica and it carries a number of diseases, especially arboviruses (arthropod-borne virus) and filariasis. It breeds basically in urban and periurban sites and has a low capacity for immigration $(0.5 \mathrm{~km})$. C. pipiens lays its eggs on standing water of high organic levels and can be found in great abundance in sewage networks, drainage canals, small wells, disused tires, sewage pits and plugged gutters. Culex tarsalis is a vector for Western equine encephalitis. Disease is spread by females. Males do not bite. The females take blood meals that are used to support the development of eggs. Culex is described as zoophagic because it takes its meals from animals as well as humans and can also be described as ornithophagic because it frequently feeds on birds. Any disease that is carried by Culex can therefore become difficult to eradicate because any animal community that it feeds on can become a reservoir and mobile species, such as birds, which can spread the disease through a large area. This was seen in 1999 in the Eastern United States when West Nile virus was introduced into the area. $C$. pipiens feeds at night. Feeding is described as endophagic because the mosquito prefers to feed in and around structures and the mosquito then rests in cool damp spots within structures while the meal is digested (endophilic behavior) (www.cbwinfo.com/Biolobical/vector/culex.html).

The use of insecticide-treated nets and curtains has now been demonstrated convincingly to substantially reduce morbidity and mortality from malaria in Nigeria, at least in the short term [23], as well as in other places [2426], and this intervention should be encouraged in these malarious areas. The correct use of insecticide-treated nets is likely to be a significant factor to reduce malaria transmission. The net, however, might not be helpful if people stay outdoors till late into the night. Although total eradication of mosquitoes may be preferable, it has been unattainable by innumerable attempts at malaria control. However, malariometric reasons why transmission can be cut by reduction in mosquito survival to infectivity better than by density reduction have been expounded [27], leading to the concept of vectorial capacity, $m a^{2} p^{n} /$ $-\log _{e} p[28,29]$ which determines malaria incidence. In this expression, $p$, the probability of mosquito survival for $n$ days, greatly outweighs the importance of mosquito density in relation to man $\left(m a^{2}\right)$.

In conclusion, malaria results in enormous economic costs which are mostly borne by the poorest people, who spend a very significant proportion of their meager income for personal protection against malaria and for treatment. This cumulative spending far outweighs the limited share of the national budget for malaria and the even smaller investment from the international community [30]. Malaria control in Africa requires a commitment at the local level not only to diagnose and treat malaria cases but also to make efforts backed by strong political will to implement regional or subregional Integrated Vector Control and for more operational researches on vectors and vector-borne diseases. This will need strong international support for its implementation and sustainability. 


\section{References}

1 Bruce-Chwatt LJ: Malaria in Nigeria. Part II. West Afr Med J 1952;1:153-158.

-2 WHO: Age-grouping methods in Diptera of medical importance with special reference to some vectors of malaria. Monogr Ser World Health Organ 1962;47:13-191.

- 3 Pinto J, Arez AP, Franco S, do Rosario VE, Palsson K, Jaenson TG, Snounou G: Simplified methodology for PCR investigation of midguts from mosquitoes of the Anopheles gambiae complex in which the vector and Plasmodium species can both be identified. Ann Trop Med Parasitol 1997;91:217-219.

4 Federal Ministry of Health, Nigeria. National Malaria Control Program Plan of Action 1996-2001.

5 Molineaux L, Grammicia G: The Garki Project. Research on the Epidemiology and Control of Malaria in the Sudan Savanna of West Africa. Geneva, WHO, 1980.

6 Okpala IE: The incidence of the female anopheline mosquito infection with human malaria parasites in the University of Nigeria, Nsukka Campus and its environs. Nig J Parasitol 1980; 1:132-147.

7 Afolabi BM: Knowledge, attitude and practice of malaria on an isolated community on the Atlantic coast of Lagos, Nigeria. Malaria Infectious Diseases Africa 1996;4:6-13.

8 Afolabi BM, Ekanem EE, Sodeinde O, Randle SA: Home, traditional and other remedies in childhood diarrhoea in coastal Nigeria. Nig $\mathbf{J}$ Paed 1994;21(suppl):121-131.

9 Gilles MT, De Meillon B: The Anophelinae of Africa south of the Sahara (Ethiopian Zoographical Region), ed 2. Johannesburg, South African Institute for Medical Research, 1968.

10 WHO: Manual on Practical Entomology in Malaria. Geneva, WHO offset publication No 13, 1975.
11 Costantini C, Sagnon NF, della Torre A, Coluzzi M: Mosquito behavioral aspects of vector-human interactions in the Anopheles gambiae complex. Parassitologia 1999;41: 209-217.

12 Fontenile D, Lochouarn L: The complexity of the malaria vectoral system in Africa. Parasitologia 1999;41:267-271.

13 Berzosa PJ, Cano J, Roche J, Rubio JM, Garcia L, Moyano E, Guerra A, Mateos JC, Petrara V, Do Rosario V, Benito A: Malaria vectors in Bioko Island (Equitorial Guinea): PCR determination of the members of Anopheles gambiae Giles complex (Diptera: Culicidae) and pyrethroid knockdown resistance (kdr) in $A n$. gambiae sensu stricto. J Vector Ecol 2002;27: 102-106.

14 Macdonald G: The Epidemiology and Control of Malaria. Oxford, Oxford University Press, 2001.

15 Birley MH, Charlewood JD: Sporozoite rate and malaria prevalence. Parasitol Today 1987; 3:231-232.

16 Smith DL, Dushoff J, McKenzie FE: The risk of a mosquito-borne infection in a heterogeneous environment. PLos Biol 2004:e368 (http://biology.plosjournals.org).

17 Takken W: The role of olfaction in host-seeking of mosquitoes: a review. Insect Sci Applic 1991;12:287-297.

18 Takken W, Knols BGJ: Odor-mediated behavior of Afrotropical malaria mosquitoes. Annu Rev Entomol 1999;44:131-157.

19 Kelly DW: Why are some people bitten more than others? Trends Parasitol 2001;17:578581.

20 Dietz K: Models for vector-borne parasitic diseases. Lect Notes Biomath 1980;39:264-277.

21 Dye C, Hasibeder G: Population dynamics of mosquito-borne disease: effects of flies which bite some people more frequently than others. Trans R Soc Trop Med Hyg 1986;80:69-77.
22 Woolhouse ME, Dye C, Etard JF, Smith T, Charlwood JD, et al: Heterogeneities in the transmission of infectious agents: implications for the design of control programs. Proc Natl Acad Sci USA 1997;94:338-342.

23 Brieger WR, Onyido AE, Sexton JD, Ezike VI, Breman JG, Ekanem OJ: Monitoring community response to malaria control using insecticide-impregnated bed nets, curtains and residual spray at Nsukka, Nigeria. Health Educ Res 1996;11:133-145.

24 Dossou-Yovo J, Diarrassouba S, Doannio J, Darriet F, Carnevale P: The aggressive cycle of Anopheles gambiae s.s. inside houses and malaria transmission in the Bouke region Cote d'Ivoire: value of using impregnated mosquito nets. Bull Soc Pathol Exot 1999;92:198-200.

25 Alonso PL, Lindsay SW, Armstrong JRM, Conteh M, Hill AG, David PH, Fegan G, de Francisco A, Hall AJ, Shenton FC, Cham K, Greenwood BM: The effects of insecticidetreated bed nets on mortality of Gambian children. Lancet 1991;337:1499-1502.

26 Lines JD, Myamba J, Curtis CF: Experimental hut trials of permethrin-impregnated mosquito nets and eave curtains against malaria vectors in Tanzania. Med Vet Entomol 1987;1:37-51.

27 White GB: Malaria prevention by vector control: effectiveness of insecticidal methods. Parasitologia 1999;41:385-387.

28 Garrett-Jones C: Prognosis for interruption of malaria transmission through assessment of the mosquito's vectorial capacity. Nature 1964;204:1173-1174.

29 Garrett-Jones C, Grab B: The assessment of insecticidal impact on the malaria mosquito's vectorial capacity, from data on the proportion of parous females. Bull World Health Organ 1964;31:71-86.

30 Bosman A, Kassankogno Y, Kondrachine AV: Implementation of malaria control. Parasitologia 1999;41:391-393. 